\title{
Irrational human behaviour. what is to blame: our brain or the mind? strategies for dealing with preconceived ideas on depression and obesity
}

\section{Preamble}

Dedicated to those who are a victim of their own erroneous perceptions and anxieties that seem too difficult to understand and deal with. However we are all entitled to a fulfilling and long life, not stifled by ill health. In order to do so, WE, each of us personally, need to take full control of that life. This paper will show a practical and proven way to accomplish this.

\begin{abstract}
All is not well with human society. From the earliest beginnings we appear to have little or no perception of what life is all about between our birth and demise and everything in between. Perhaps our problems already exist by not having been provided with a 'how to live' user manual for ourselves and our parents. For that reason we have to basically 'reinvent the wheel' like so many others have done before us. So we all have to start from scratch like everyone else or do we? About a decade ago, a TV broadcaster aired a program that I recall was named YEAR ONE. IT was an investigation into a child's life from birth until Year 1. Babies from diverse socio-economic background had been chosen for observation on variations in their daily behaviour and activities. These were subsequently recorded and dispersed over a number of interesting episodes. Whilst there were recognisable similarities in behaviour between the subjects, moving about on the floor did show significant difference that could be categorised in three ways, i.e. cross crawling, lateral crawling and moving about on the behind. It was interesting to note that after completion of the first year, the subjects using 'cross crawl' identified as right arm and left knee brought forward, followed by the left arm and right knee brought forward as well as those practising lateral craw, i.e. using first one side than the other developed a normal intellect with the cross crawlers performing better. A small group did not crawl but moved about in a sitting position. What appears remarkable is that the cross crawler developed a balanced intellect, with a poorer performance from lateral crawling. However babies moving about on their bums suffered pruning of what intellect they had developed before the 'year one' was reached.
\end{abstract}

It is not really such a mysterious happening if we understand that the growth of the brain has gone to some considerable lengths to create physiological balance and simultaneously also psychological balance by having the nerves from the left hemisphere crossing into our body on the right side and nerves from the right hemisphere moving down into the left side. This strategy enables our sub-conscious to keep track of our physical balance, i.e. remaining straight and upright, by constantly adjusting for equal muscle tension on both sides. The purpose of this essay is to point out the value of NEGATIVE biofeedback and associated BRAIN SWITCHING for survival and so diminish fatalistic tendencies in our behaviour, including obesity and depression. No attempt has been made to present statistical information about being overweight and or obese other than stating the obvious such as being at least $40 \mathrm{~kg}$ over weight or double the normal weight due to accumulated fat in comparison to the normal expected weight of an individual and its height. Instead an effort is made to address the problem of depression and obesity by increasing awareness of psychological adjustments open to those suffering from these afflictions and the multitude of health problems that originate from that.
Volume 7 Issue 2 - 2017

Hans Laroo

Independent Researcher, Australia

Correspondence: Hans Laroo, Independent Researcher, 7 Vineyard Street, one mile and laroo4305, Australia, Email hlaroo@bigpond.com

Received: June 16, 2017 | Published: August 07, 2017

Keywords: negative biofeedback, brain, mind, survivalist, fatalism, depression, obesity

\section{Introduction}

Life for humans is very complex and in particular making decisions on what to do or not do for one self and others. Everything is interconnected in the Universe as nothing can get in or out. We and everything else in whatever form has to accept that situation as well as the fact that we only live once in this life. To deal with such situations, we have been endowed with a brain and a mind. Contrary to popular 
belief, the brain and the mind are not the same thing. The brain by all accounts is a physical thing that can grow from a single cell, but can also get damaged and die. The mind should be seen as a form of latent energy that allows us to think and make the two halves of our brain, the left and right hemisphere, communicate with one another by means of the large number of nerves connecting both hemispheres, called the Corpus Callosum. There are differences between the left and right brain that are often in conflict when either the left or right becomes dominant. When that occurs the brain/mind and body are disturbed and loses its balance. It is generally understood that there are two aspects of the brain, with the left brain being akin to digital processing and the right brain more analogue orientated. Generally the attributes of left and right brain can be listed as follows Table $1 .^{1}$

Table I The attributes of left and right brain

\begin{tabular}{ll}
\hline Left brain & Right brain \\
\hline Survivalist orientated \& hunting & Fatalistic orientated \\
Logical \& mathematically & Emotional \& adherence to belief systems \\
$\begin{array}{l}\text { Verbal expression \& common } \\
\text { sense }\end{array}$ & Poor expression in writing \\
Block letter writing & Long hand writing \\
Vertical \& focus & Horizontal \& broad picture approach \\
Precision & Imprecision \& lack of detail \\
Counting \& rhythm & Melody \& lyrics \\
Two dimensional & Spatial ability \\
Objective & Subjective \\
\hline
\end{tabular}

Note! Not all of these attributes are listed, but those that are, do show the vast differences in perception of the world around us and are indicative what we favour to respond to as evidenced by our crossed nervous system from left to right and vice versa as related to sounds as an example. Visualise an orchestra, violins and flutes on the left, high pitched and emotional sustained as compared to drums, cellos and other percussion instruments and low tones providing the rhythm on the right. This means that we use our right ear and our left brain to listen to the rhythm and with our left ear and right brain seek out the higher pitched sounds that are sustained. Even our recordings are produced with this in mind. Likewise we use our left brain when writing block letters but when it is necessary to write long-hand than the two must work together. Hunting is also done this way, when the spear is thrown or the bow and arrow pointed at the target, both brain halves must cooperate in both strength and spatial abilities. The need to harmonise is always the best strategy and not doing so will prove disastrous in most cases. It is here where biofeedback practises reach centre stage. There are two types of feedback, controlling (negative) and destructive (positive). ${ }^{2,3}$

\section{Negative and positive feedback}

Both negative and positive feedback systems occur in Physics and Technology, such as the governor in an engine or the escarp mechanism in a clock. Generally speaking, negative feedback is a controlling mechanism and an excellent example is negative or inverted feedback applied to a public address or music amplifier system. It takes some of the energy it produces and presents this in an inverted form to the input to not only reduce its output but to also stop any so-called 'run-away'. If such practices are adopted and part of the output signal reaches the input without change or inversion, it will add to the already amplified system and become an out of control oscillator that if allowed to continue, will self-destruct. We would all be familiar with a microphone causing "HOWL"! Positive feedback is thus destructive and in humans, this can be very injurious and even fatal. Positive feedback in humans can occur if the person involved can see no other way but to constantly/repetitively reinforcing thinking about a problem, i.e. I have a problem, I have a problem, I have a problem etc, etc, and eventually be driven to utter despair. The application of negative feedback can reverse the situation by simply acknowledging that there is a problem and seek a solution to the problem. A problem is immediately diffused but it does take some intelligence and discipline to embrace such strategies. ${ }^{4}$

Note! One type of measure of intelligence is not what we know or have learned, but the ability to deal with whatever problem arises and immediately seek a solution, even if it is the wrong solution. This can happen during the so-called "Agony of the Moment" when a person is suddenly confronted with a situation created by someone else, i.e. 'being on the wrong side of the road'. It is actually a Defence at Law.

The best thing to do when faced with a problem, is to take a sheet of paper and a pen or pencil and write down every possible option in order to deal with the problem. It is surprising how easy an apparent serious problem will quickly dissipate.

Applying NEGATIVE feedback is an answer to most problems as thinking about what to do or not do next, an informed decision can be made by being aware of the most likely consequences to one self and others. Constantly thinking and craving for food, drugs, alcohol, money and attention only exacerbates the problems. It is constantly reinforcing these damaging thoughts. And it only gets worse giving in as it programs the brain to accept nothing less. The only way out is BRAIN SWITCHING.

\section{Switching the brain}

Switching our brain is in all cases the best option and the faster this occurs between left and right brain the more we can be considered balanced both physiologically and psychologically. Ways to do so is done by very low impact exercises or body movements where simultaneously both arms and/or legs are activated. This then also activates the entire nervous system and actually repairs and maintains as well as make new nerve connections throughout the entire body. It is called kinesiology and most of these body movements can be found in the Chinese (internal) martial arts called Qi Gong, literally meaning MAKING ENERGY WORK, Tai Chi, Yoga etc. What also needs to happen is accompany these two sided body movements with counting and focussing the mind at the same time, i.e. concentrating only on the exercise. ${ }^{5}$ The philosophy behind this is as follows:

When we are born and even before and still in the wombs, vibrations, smells and light sensory observations are beginning to be noticed and if repeated often enough also remembered. Consuming nourishment, bombarded with information such as temperature changes and our parents talking to us at first seem bewildering. Eventually we start to make sense of it all but for our own self-awareness. That is a problem in itself, as in fact some people even late in life Do Not Know Who They Are and never will! This is comes about when not applying negative feedback, always acing impulsively and not learning from the past or worrying about the future, but instead only living in the "NOW". 
"This behavioural attitude is fatalistic thinking as it always has bad outcomes and making that person their own worst enemy".

A way forward from this situation can be done by constant brain switching, being aware of all times, i.e. (a) what happened in the past, (b) what is happening right now and (c) and what is the likely outcome in the future and then making an informed decision about what to do. The level of precision in our actions and reactions will determine what these outcomes will be. For instance when filling a glass with alcohol and saying to oneself "just one" is very precise, but taking more and more is imprecise..$^{6-8}$

The second strategy is just as important. It is learning what one can do and not do as well as to know and not know and what cannot be accomplished and not. The idea of applying negative feedback is to acknowledge what has been learned so far and then concentrating on all of those new things we are not familiar with until we do. That way we will get to know more and more about ourselves through acquiring new skills. Such activities increases our self-esteem, self-confidence, discipline and providing us with ever increasing abilities and able to cope with whatever chance brings. More importantly we get to know ourselves and we will hardly ever feel depressed and in need of a 'crutch like behaviour' by consuming too much food and addictive substances for a short period of deluded well-being. ${ }^{9-11}$

It is relatively easy to determine the dominant side of the brain by determining the muscle tension in our extremities. Ask a subject to place their arms lifted sideways just below shoulder height whilst slowly rotating in a clock or counter clock-wise motion. The inactive brain half will make the arm on the opposite side droop just a bit in control of the non-dominant brain halve., i.e. If the right (subjective) brain is in charge the left arm it will indicate insufficient muscle tension and tend to droop. Many children with learning difficulties in mathematics and precise expression will demonstrate such shortcomings, as well as other more subtle changes. For instance an inactive left brain will make tapping the beat of the music just about impossible by some.

\section{The golden rules for obesity on which this essay is concentrating}

a. Get engaged in doing regular low impact body movements or exercises as recommended aforementioned. However embarking on any exercise program, no matter what type it is prudent to start with just a few and generally over time increase their number until 100 is reached. At all times be mindful of the effect and notice anything that may not feel right and stop until such time that it feels better. Think about the exercises you are doing and what effect if any it has on you. Do not think of anything else.

b. Eat healthy foods, preferable self-prepared and cooked at relatively regular pre-set times. It must be understood that there is a very specific need for nourishment consisting of minerals, vitamins and the essential sugars, amino acids (proteins) and fatty acids (both high and low cholesterols) in order to keep our body and pro-biotic gut bacteria happy. Diversity in vegetables is very important. No doing so will cause upsets and rebellion amongst your cells and others.

c. Sleep during the night and be active during the day. During the day our sympathetic nervous system is active and during the night our Para Sympathetic nervous system takes over for REST and DIGEST. Interfering with the hormones released at the wrong time when doing the reverse by staying up too late and sleeping in the next morning may prove counterproductive.

d. Dispel any thoughts on eating more and seek activities that assist in thinking about other more important matters, such as looking after yourself.

e. Do not diet, just continue eating the right food and build muscles instead so that loose and ugly derma will be minimised when excess fat is lost.

f. To understand that it is the individual exclusively that is able to reverse the situation for any addiction or adopted tendency. It is the individual's choice to stop or continue. There is really nothing to it, but by continually remaining stubborn, deluded, in self-denial or other invalid argument, this battle cannot be won. ${ }^{11-17}$

\section{Conclusion}

Observation and investigation over many decades has confirmed that subjective and emotional decisions, generally impulsive, create bad outcomes. However conscious and careful thoughts based on common sense and logic do not suffer from the same fate. It all comes down to being precise instead of approximate, applying negative feedback to our thoughts and avoiding mindless behaviour, using subterfuges like complacency and embracing the 'easy way out'. Often in hindsight it is then realised that more attention to the problem would have provided a better outcome. That these rules work is evidenced by an actual event to the author personally. Details on how the body was able to repair itself are as follows:

"In mid-January in 1992. It was midnight, I woke up and lifted my head to look at the LED clock located in the left corner of the bedroom. To my amazement the clock seemed to move across the room to the far right. I shook my head in disbelief and lo and behold, the clock was back where it belonged. However a few seconds later the same thing happened. This time, I sat up to try and understand, only to be thrown out of bed onto the floor and vomiting profusely. All I could do to obtain some stability was to lay flat on my back with my legs and arms spread wide and remained there for the next 24 hours, unable to move or get up. A doctor was called and declared that I was suffering from food poisoning. This was six months later amended to a damaged eight cranial nerve causing an extremely violent form of vertigo and nystagmus (uncontrolled rolling of the eyes). I was told that I would never function properly and work again. We sold our house and with mounting debts and moved to a cheaper neighbourhood ready to vegetate. I was indeed incapable of much at all having almost no balance left. At some stage I came across a book on Qi Gong and started practicing the exercises illustrated therein, day in day out. It took around 4 years of disciplined exercises and special body movements to not only find complete healing and being fitter and stronger than ever before. At 70 years of age I was doing pushups at full arms-length, i.e. just resting on my toes and fingers from outstretched arms and teaching others for free for several years. I will be 81 in a few weeks of completing this paper".

\section{Acknowledgements}

None.

\section{Conflict of interest}

The author declares no conflict of interest. 


\section{References}

1. Freeman WH, Co. Left Brain Right Brain: perspectives on cognitive neuroscience. Sally P Springer and George Deutsch; 1998. 406 p.

2. Robert Firnhaber White. Understanding Brain Damage- a Primer of Neuropsychological Evaluation. Journal Clinical Neuropsychologist. 2007;3(2):193-196.

3. George Serban. The tyranny of Magical Thinking - The Child's World of Belief and Adult Neurosis. USA: Dutton; 1983.

4. John N Demos. Getting started on Neuro Feedback. USA: WW Norton \& Company; 1923.

5. Allan Parker, Margaret Cutler-Stuart, Paul E Dennison. Switch on your brain. 2007.

6. Derek, Julia Parker. How do you know who you are? England: Macmillan Publishing Co. Inc; 1980.

7. Neil R Carlson, Allyn, Bacon. Foundations of Physiological Psychology. USA: Viacom Company; 1999.

8. Judith Green, Robert Shellenberger. The Dynamics Of Health \& Wellness-A Biopsychosocial Approach. Biofeedback Training. 1990:220-252.
9. Edward C Chang. Knocking at the Gate of Life: Healing Exercises from the Official Manual of the People's Republic of China. Australia: New Holland Publishers Pty Ltd; 2000.

10. Yang J wing-Ming. The Root of Chinese Chi Kung: The secrets of Chi Kung training. USA: Yang's Martial Arts Association (YMAA); 1989.

11. Luigi (Eugene Louis Facciuto), Kenneth Wydro. The Luigi Jazz Dance Technique. 1981.

12. Carlos Castaneda. Magical Passes: The Practical Wisdom of the Shamans if Ancient Mexico. USA: Harper Perennial; 1998.

13. Edwin F Flatto. USA: Miracle Exercises Instant Improvement Inc; 1992.

14. Daniel Reid. The TAO of Health, Sex \& Longevity: A Modern Practical Approach to the Ancient Way. UK: Simon \& Schuster; 1989.

15. Daniel Reid. Guarding the three Treasures. UK: Simon \& Schuster; 1993.

16. Daniel Reid. A complete guide to Chi-Gung. USA: Shambhala Publications Inc; 1998.

17. Leonard Schwartz. Heavy Hands-A Unique Contribution. 1983 